\title{
Numerical Study on Pounding between Two Adjacent Buildings under Earthquake Excitation
}

\author{
H. Naderpour, ${ }^{1}$ R. C. Barros, ${ }^{2}$ S. M. Khatami, ${ }^{1}$ and R. Jankowski ${ }^{3}$ \\ ${ }^{1}$ Faculty of Civil Engineering, Semnan University, Semnan 3513119111, Iran \\ ${ }^{2}$ Faculty of Engineering, University of Porto (FEUP), 4200-465 Porto, Portugal \\ ${ }^{3}$ Faculty of Civil and Environmental Engineering, Gdansk University of Technology, 80-233 Gdansk, Poland
}

Correspondence should be addressed to R. Jankowski; jankowr@pg.gda.pl

Received 30 July 2015; Accepted 15 October 2015

Academic Editor: Georges Kouroussis

Copyright (c) 2016 H. Naderpour et al. This is an open access article distributed under the Creative Commons Attribution License, which permits unrestricted use, distribution, and reproduction in any medium, provided the original work is properly cited.

\begin{abstract}
Seismic excitation, which results in large horizontal relative displacements, may cause collisions between two adjacent structures due to insufficient separation distance between them. Such collisions, known as earthquake-induced structural pounding, may induce severe damage. In this paper, the case of pounding between two adjacent buildings is studied by the application of single degree-of-freedom structural models. Impact is numerically simulated with the use of a nonlinear viscoelastic model. Special attention is focused on calculating values of impact forces during collisions which have significant influence of pounding-involved response under ground motions. The results of the study indicate that the impact force time history is much dependent on the earthquake excitation analyzed. Moreover, the peak impact forces during collision depend substantially on such parameters as gap size, coefficient of restitution, impact velocity, and stiffness of impact spring element. The nonlinear viscoelastic model of impact force with the considered relation between the damping coefficient and the coefficient of restitution has also been found to be effective in simulating earthquake-induced structural pounding.
\end{abstract}

\section{Introduction}

During ground motions, buildings often collide with each other due to different dynamic characteristics, insufficient gap between them, and out-of-phase vibrations [1]. The phenomenon related to such collisions is often called the earthquake-induced structural pounding. Pounding is expressed by an instance of rapid strong pulsation, which may cause severe damage [2]. Consequently, the probability of structural interactions during earthquakes must be assessed. A number of researchers have studied the problem of pounding for different structural configurations under various ground motions:

(i) Anagnostopoulos [3] was among the first scientists who investigated the earthquake-induced structural pounding by analyzing interactions between buildings in a row. He also described in detail the threats related to such collisions during ground motions [4]. (ii) Maison and Kasai [5] presented a formulation and simulated the multi degree-of-freedom equations of motion for floor-to-floor pounding between two 15storey and 8 -storey buildings. The influence of building separation, relative mass, and contact location properties was investigated.

(iii) Jankowski [6,7] and Mahmoud et al. [8,9] carried out a number of studies concerning structural pounding, related to both experimental and numerical aspects.

(iv) Komodromos et al. [10-12] studied pounding between seismically isolated buildings.

(v) Barros and Khatami [13] examined a new model of impact to coordinate of results among numerical and experimental studies. They also suggested an approximate trend to select coefficient of restitution, which becomes equal to impact velocity [14]. Subsequently, a new equation of motion was suggested to simulate impact and figure damping terms out of collision [15]. 
Furthermore, some more recent numerical analyses have been carried out to study the influence of different parameters in pounding of buildings [16-20].

Nevertheless, there is still a need to investigate different models of structural pounding so as to verify their accuracy in the case of different configurations under different earthquake excitations. This concerns especially the values of impact forces during collisions which are often not studied in the analyses (or the analyses are simplified) since the investigations are rather focused on pounding-involved response under ground motions.

\section{Contact Element Methods}

The contact element is a special element (usually consisting of a spring and damper) to model impact between two colliding structures, which is widely used to simulate impact force. Impact is parametrically modelled in this way that when relative displacement exceeds the separation distance, the contact element is activated. The general formula for the impact force during collision can be expressed as follows (see [21]):

$$
F_{\text {imp }}(t)=k_{s} \cdot \delta^{n}(t)+c_{\text {imp }}(t) \cdot \dot{\delta}(t)
$$

where $k_{s}$ is stiffness of spring, $c_{\text {imp }}(t)$ denotes damping of dashpot, and $\delta(t)$ and $\dot{\delta}(t)$ describe lateral displacement and velocity, respectively. The power of $n$ has been recommended to be 1 or 1.5 depending on the model considered. The damping coefficient $c_{\text {imp }}(t)$ is usually related to the coefficient of restitution CR which is defined as the ratio between the postimpact velocity $\dot{\delta}_{\text {rebound }}$ and the prior-impact velocity $\dot{\delta}_{\text {imp }}[21]$ :

$$
0<\mathrm{CR}=\frac{\dot{\delta}_{\text {rebound }}}{\dot{\delta}_{\text {imp }}}<1 .
$$

Anagnostopoulos. The linear viscoelastic model of impact force (with $n=1$ ) was considered by Anagnostopoulos [3]. The following formulae were suggested $[3,22]$ :

$$
\begin{aligned}
c_{\text {imp }}(t) & =2 \cdot \zeta \cdot \sqrt{k_{s} \cdot \frac{m_{i} m_{j}}{m_{i}+m_{j}}} \\
\zeta & =\frac{\ln (\mathrm{CR})}{\sqrt{\pi^{2}+(\ln (\mathrm{CR}))^{2}}},
\end{aligned}
$$

where $m_{i}, m_{j}$ are the masses of colliding structures. The impact force versus time and lateral displacement for the linear viscoelastic model is shown in Figure 1.

Jankowski. Jankowski [6] considered the nonlinear viscoelastic model when $n=1.5$. He proposed activating the damping term only during the approach period, in which most of the energy is lost. Therefore, the following formulae were considered [6]:

$$
\begin{aligned}
F_{\text {imp }}(t) & =k_{s} \cdot \delta^{n}(t)+c_{\text {imp }}(t) \cdot \dot{\delta}(t) \longrightarrow \\
\dot{\delta}(t) & >0 \text { (approach period) } \\
F_{\text {imp }}(t) & =k_{s} \cdot \delta^{n}(t) \longrightarrow \\
\dot{\delta}(t) & \leq 0 \text { (restitution period) } \\
c_{\text {imp }}(t) & =2 \cdot \zeta \cdot \sqrt{k_{s} \sqrt{\delta(t)} \cdot \frac{m_{i} m_{j}}{m_{i}+m_{j}}} .
\end{aligned}
$$

It was suggested that the appropriate value of impact damping ratio $\zeta$ for a specified value of $\mathrm{CR}$ can be obtained numerically through iterative simulations in order to satisfy the relation between the postimpact and the prior-impact velocities defined by (2) [6]. The following formula was also proposed [9]:

$$
\zeta=\frac{9 \sqrt{5}}{2} \cdot \frac{\left(1-\mathrm{CR}^{2}\right)}{\operatorname{CR}(\mathrm{CR}(9 \pi-16)+16)} .
$$

An alternative approach might also be needed to consider the relation between the damping coefficient $c_{\text {imp }}(t)$ and the coefficient of restitution $\mathrm{CR}$ in the following form:

$$
c_{\text {imp }}(t)=\alpha \cdot \frac{\mathrm{CR}^{\beta} \dot{\delta}_{\text {imp }}(1-\mathrm{CR})}{\ddot{\delta}(t)} \cdot k_{s} \cdot \delta^{n}(t),
$$

where $\alpha$ and $\beta$ are the parameters of the model obtained by fitting the experimental data using the method of the least squares (determined in this way typical values are $\alpha=0.01557, \beta=0.2706$ ). As it can be seen from (7), the impact damping coefficient depends directly on the prior-impact velocity value, which can be obtained for each impact separately. The impact force versus time and lateral displacement for the nonlinear viscoelastic model is shown in Figure 2.

Muthukumar and DesRoches. A different model (Hertzdamp model) was considered by Muthukumar and DesRoches [23]. They presented a formula for the impact force during collision with $n=1.5$, which depends on three parameters, including coefficient of restitution, stiffness of spring, and prior-impact velocity, as

$$
\begin{aligned}
c_{\mathrm{imp}}(t) & =\zeta \cdot \delta^{n}(t) \\
\zeta & =\frac{3 \cdot k_{s}\left(1-\mathrm{CR}^{2}\right)}{4 \cdot \dot{\delta}_{\mathrm{imp}}} .
\end{aligned}
$$

The impact force versus time and lateral displacement for the Hertzdamp model is shown in Figure 3.

Ye et al. Ye et al. [24] claimed that (9) is incorrect to calculate the damping ratio for the pounding simulation in order to 

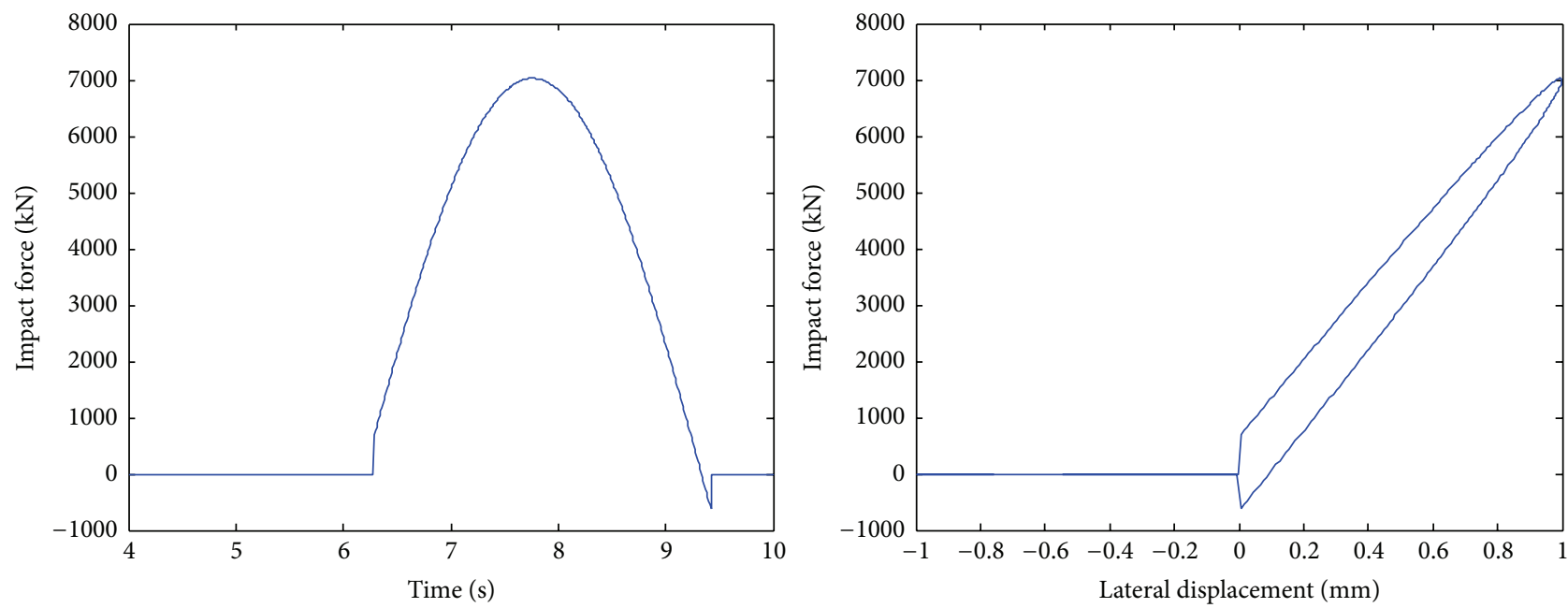

FIGURE 1: Impact force versus time and lateral displacement for the linear viscoelastic model.
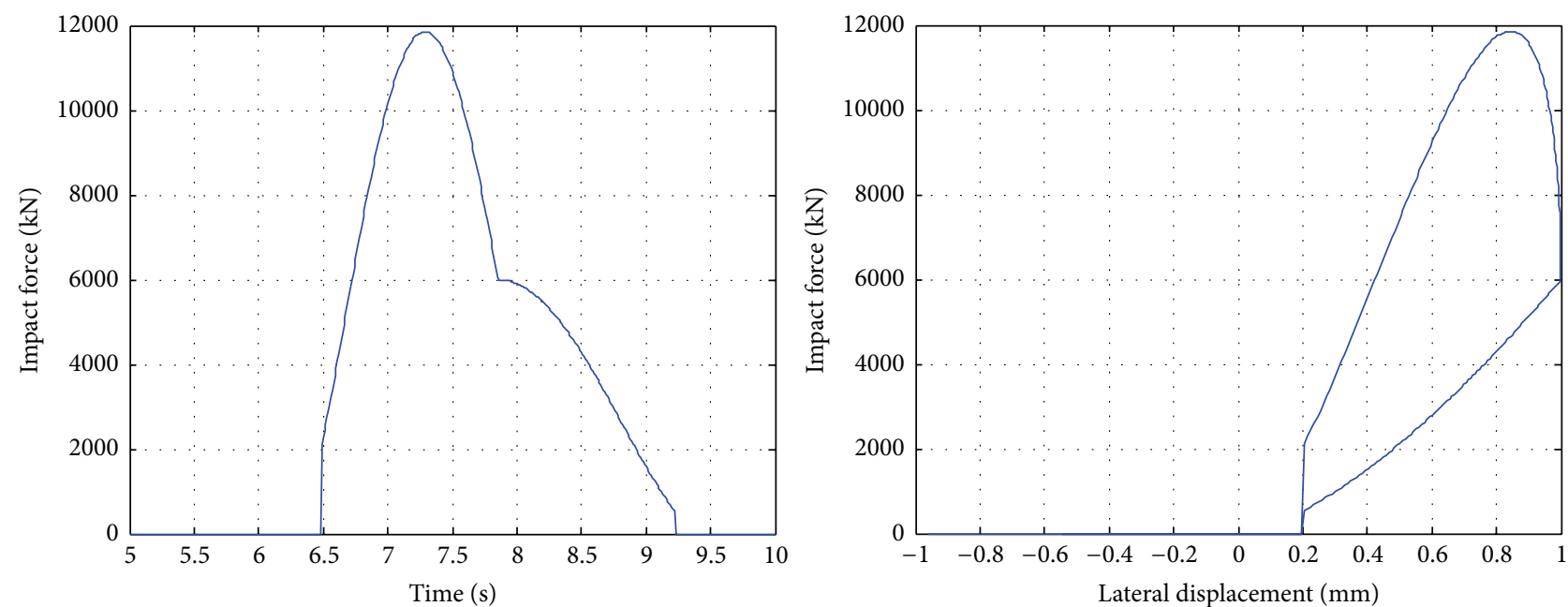

FIGURE 2: Impact force versus time and lateral displacement for the nonlinear viscoelastic model.
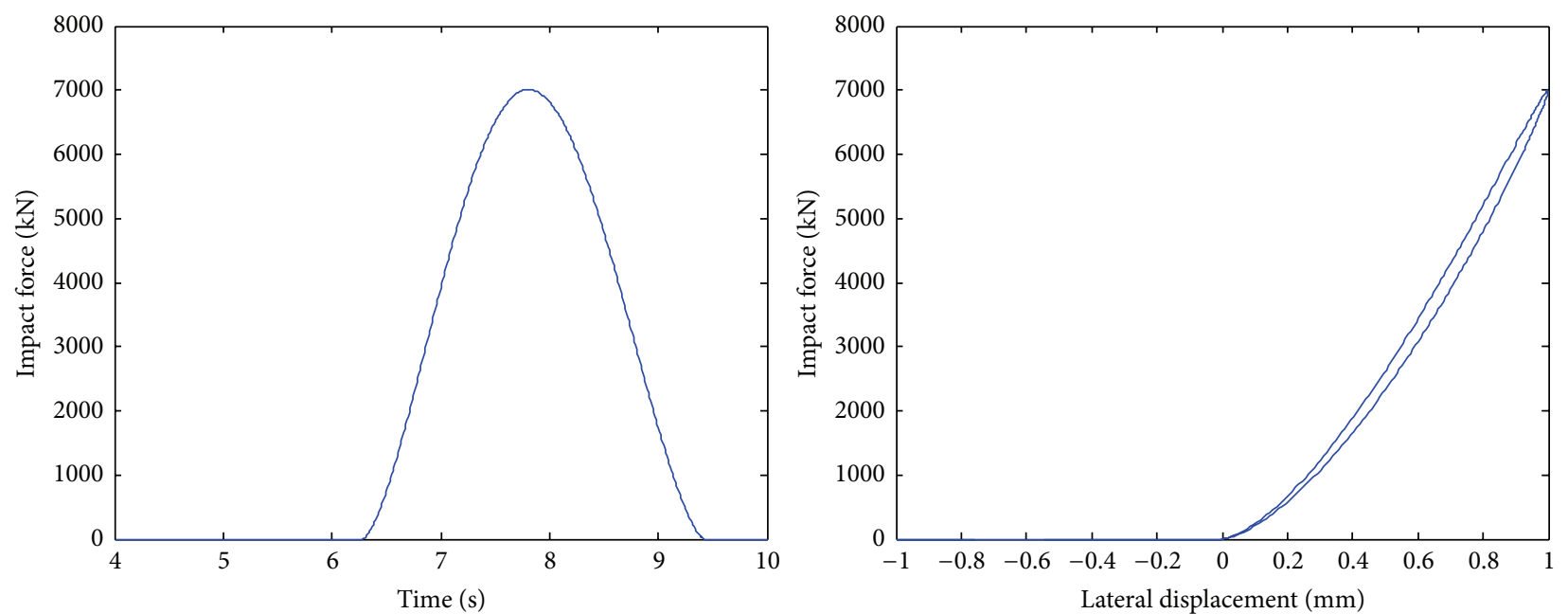

FIGURE 3: Impact force versus time and lateral displacement for the Hertzdamp model. 

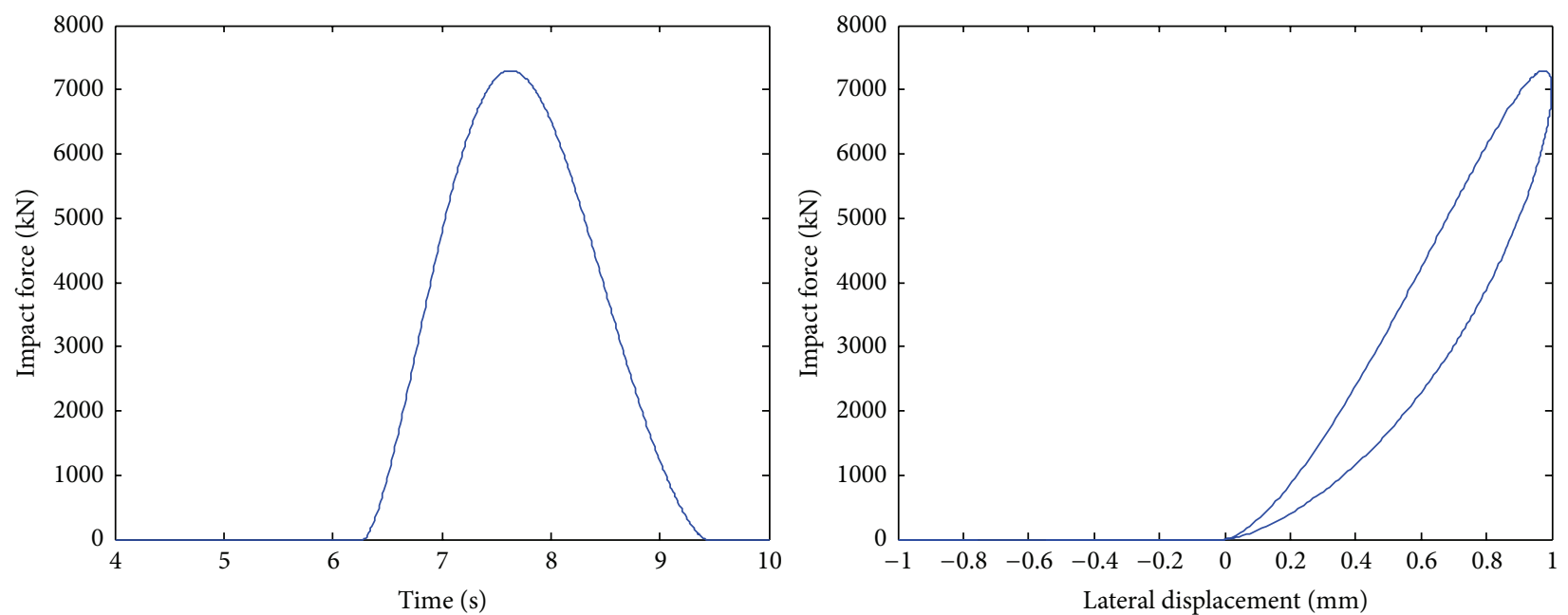

FIGURE 4: Impact force versus time and lateral displacement for the modified Hertzdamp model.

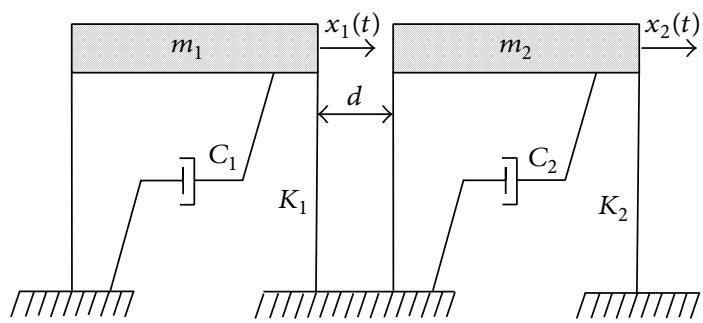

Figure 5: Model of interacting structures.

evaluate impact between two buildings. They numerically indicated that the appropriate relation is [24]

$$
\zeta=\frac{8 \cdot k_{s}(1-\mathrm{CR})}{5 \cdot \mathrm{CR} \cdot \dot{\delta}_{\mathrm{imp}}}
$$

The impact force versus time and lateral displacement for the modified Hertzdamp model is shown in Figure 4.

\section{Numerical Study}

A parametric study has been conducted in order to verify the effectiveness of the nonlinear viscoelastic model of impact force during structural pounding described by (4) and (7). Two single degree-of-freedom systems (see Figure 5) with the gap size of $d=2 \mathrm{~cm}$ have been used to model the behaviour of adjacent structures under ground motions.
The dynamic equation of motion for such a model can be expressed as [25]

$$
\begin{gathered}
{\left[\begin{array}{cc}
m_{1} & 0 \\
0 & m_{2}
\end{array}\right]\left[\begin{array}{l}
\ddot{x}_{1}(t) \\
\ddot{x}_{2}(t)
\end{array}\right]+\left[\begin{array}{cc}
C_{1} & 0 \\
0 & C_{2}
\end{array}\right]\left[\begin{array}{l}
\dot{x}_{1}(t) \\
\dot{x}_{2}(t)
\end{array}\right]} \\
+\left[\begin{array}{cc}
K_{1} & 0 \\
0 & K_{2}
\end{array}\right]\left[\begin{array}{l}
x_{1}(t) \\
x_{2}(t)
\end{array}\right]+\left[\begin{array}{c}
F_{\text {imp }}(t) \\
-F_{\text {imp }}(t)
\end{array}\right] \\
=-\left[\begin{array}{cc}
m_{1} & 0 \\
0 & m_{2}
\end{array}\right]\left[\begin{array}{l}
\ddot{x}_{g}(t) \\
\ddot{x}_{g}(t)
\end{array}\right],
\end{gathered}
$$

where $x_{i}(t), \dot{x}_{i}(t), \ddot{x}_{i}(t), C_{i}, K_{i}$ are the horizontal displacement, velocity, acceleration, damping coefficient, and stiffness coefficient for structure $i(i=1,2)$, respectively, $\ddot{x}_{g}(t)$ stands for the acceleration input ground motion, and $F_{\text {imp }}(t)$ is the pounding force which is equal to zero when $\delta(t) \leq 0$ and is defined by (4), when $\delta(t)>0$, where $\delta(t)$ is defined as

$$
\delta(t)=x_{1}(t)-x_{2}(t)-d .
$$

In the numerical analysis, stiffness of each structure has been taken to be $K_{1}=K_{2}=740 \mathrm{MN} / \mathrm{m}$ and storey masses have 


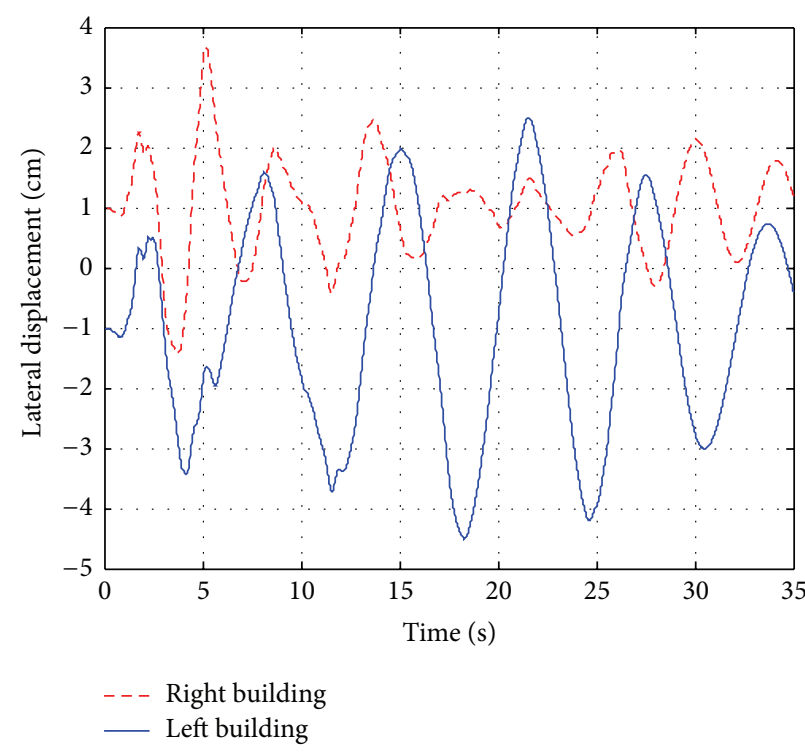

(a) El Centro

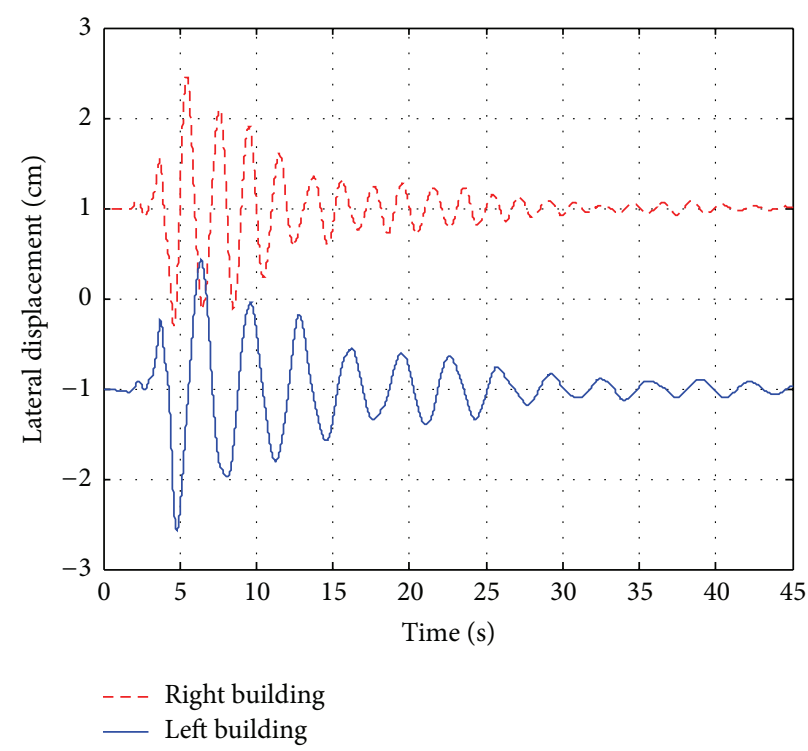

(c) San Fernando

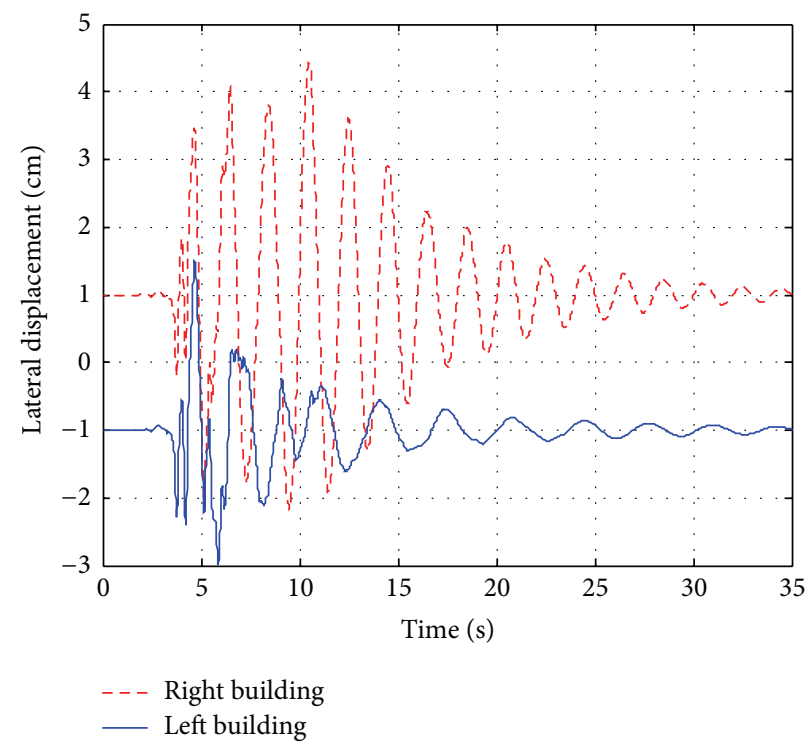

(b) Kobe

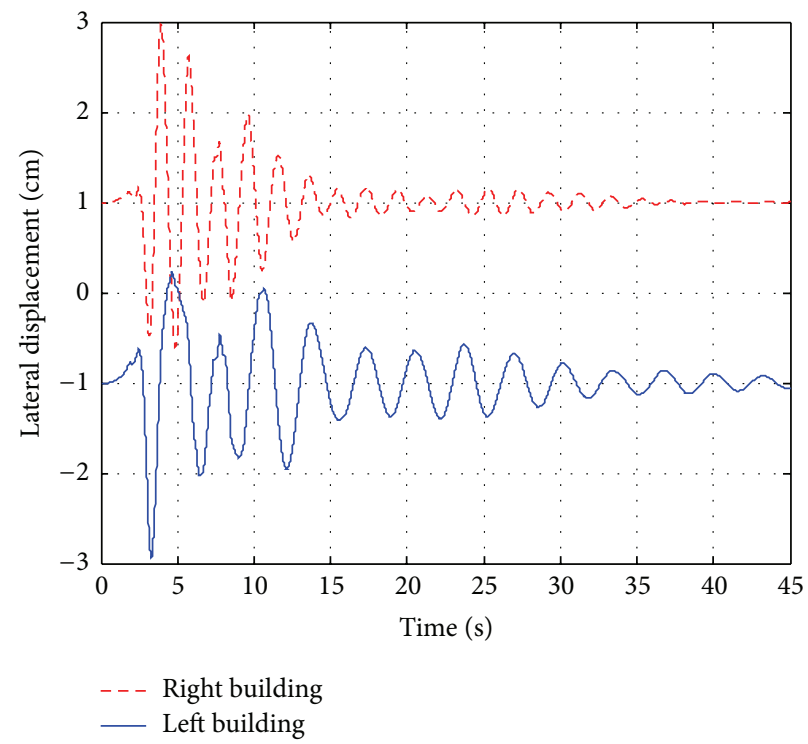

(d) Parkfield

FIGURE 6: Lateral displacement time histories under different earthquakes.

been assumed to be $m_{1}=110$ tons and $m_{2}=145$ tons, respectively. The structural damping ratio of 0.05 has been considered in the analysis.

The dynamic analyses under the Parkfield (1966), San Fernando (1971), Kobe (1995), and El Centro (1940) earthquake records have been performed. These records have different contents of the excitation frequencies, different magnitude of the accelerations, and different time durations. Besides, their place of occurrence and geological conditions close to the epicentre are distinct. San Fernando earthquake had the highest Peak Ground Acceleration (PGA) among the four records discussed. The PGA of the earthquake amounted to
$1.164 \mathrm{~g}$, with an epicentre distance less than $12 \mathrm{~km}$. The PGA of the Kobe earthquake was $0.7105 \mathrm{~g}$ and it was measured at a distance of $18.3 \mathrm{~km}$. The PGA of the Parkfield earthquake was equal to $0.462 \mathrm{~g}$ (measured at a distance of $32 \mathrm{~km}$ ). Finally, the PGA of the El Centro earthquake was equal to $0.347 \mathrm{~g}$. All mentioned records have been normalized to investigate the effect of earthquake properties on pounding-involved structural response. The examples of the results of the numerical analysis in the form of the lateral displacement time histories under different earthquakes are shown in Figure 6. Additionally, the examples of the impact force time histories for the 


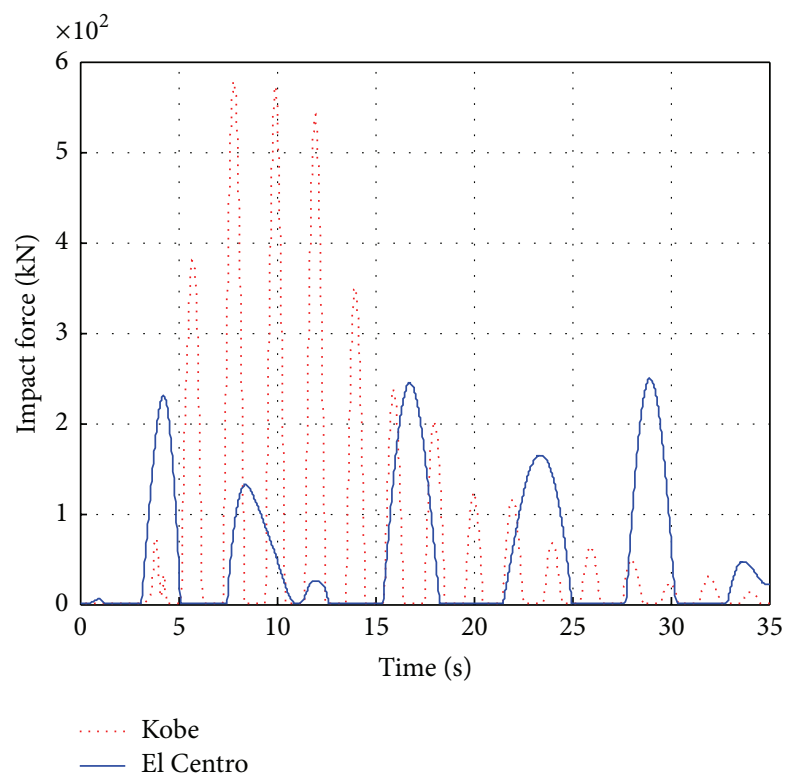

FIGURE 7: Impact force time histories for the Kobe and El Centro earthquakes.

Kobe and the El Centro earthquakes are presented in Figure 7.

Using four different earthquake excitations, the peak lateral displacements, velocities, and accelerations have also been calculated for different structural periods of colliding structures. The results of the analyses are presented in Figure 8. They indicate that, with the increase in the structural period, the peak lateral displacements show the nonuniform increase trend. Among the ground motions analyzed, the Kobe record gives the maximum lateral peak displacement equal to $3.87 \mathrm{~cm}$, while the minimum peak displacement of about $0.64 \mathrm{~cm}$ has been observed for the Parkfield earthquake. In the case of velocity, when the structural period is increased, the peak velocities are nearly the same in the range of 1-4 sec and after that the curves show a sudden decrease trend. Slightly different trend is observed for the El Centro record which demonstrates a slight increase from $5.1 \mathrm{~m} / \mathrm{s}$ to $7 \mathrm{~m} / \mathrm{s}$ and, subsequently, shows a sharp decline to $2.64 \mathrm{~m} / \mathrm{s}$ when the structural period changes its value from 1 to $9 \mathrm{sec}$. Finally, the peak acceleration curves are quite stable at the beginning of analyzed range of structural period and then they show a substantial increase trend.

3.1. Effect of Gap Size. In order to investigate the effect of separation distance between structures, a gap size has been varied from 0 to $8 \mathrm{~cm}$. Figure 9 shows the effect of separation distance on the peak impact force under four different earthquake records. It can be seen from the figure that the curves follow an irregular decrease trend when the gap size increases. In the case of the San Fernando and Kobe ground motions, a sudden decrease is observed after passing a specific gap size value, while a slight declining tendency is visible for two other earthquake records.
3.2. Effect of Coefficient of Restitution. Different values of coefficient of restitution CR have been considered to investigate the impact forces between structures under different earthquakes. The results of the investigation showing the peak values of impact forces are presented in Figure 10. Similar trend can be observed for all analyzed excitations. The results show a uniform decrease in the force when the coefficient of restitution increases. For instance, the peak impact force for the Kobe earthquake is equal to $341 \mathrm{kN}$ and $92 \mathrm{kN}$ for $\mathrm{CR}=0.1$ and $\mathrm{CR}=0.9$, respectively.

3.3. Effect of Impact Velocity. In order to obtain the responses and compare the results of peak impact forces, different values of impact velocity have been considered from the range $1-25 \mathrm{~m} / \mathrm{s}$. The relations between the peak impact force and impact velocity values under different earthquakes are presented in Figure 11. The results show a uniform increase in the peak impact forces with the increase in the impact velocity. The peak impact forces are nearly equal to zero for the velocity of $1 \mathrm{~m} / \mathrm{s}$ and are as large as $1725 \mathrm{kN}, 1578 \mathrm{kN}$, $1560 \mathrm{kN}$, and $1405 \mathrm{kN}$ for the $25 \mathrm{~m} / \mathrm{s}$ impact velocity under the El Centro, Kobe, San Fernando, and Parkfield earthquake, respectively.

3.4. Effect of Stiffness of Impact Spring. Stiffness of impact spring element is considered to be one of the most important parameters when the impact force during collision is calculated. The results of the parametric study showing the peak values of impact forces with respect to stiffness of spring are presented in Figure 12. It can be seen from the figure that the trend for all earthquakes analyzed is similar. The impact forces show nearly linear increase from $210 \mathrm{kN}$, $214 \mathrm{kN}, 273 \mathrm{kN}$, and $352 \mathrm{kN}$ to $2122 \mathrm{kN}, 2242 \mathrm{kN}, 2625 \mathrm{kN}$, and 

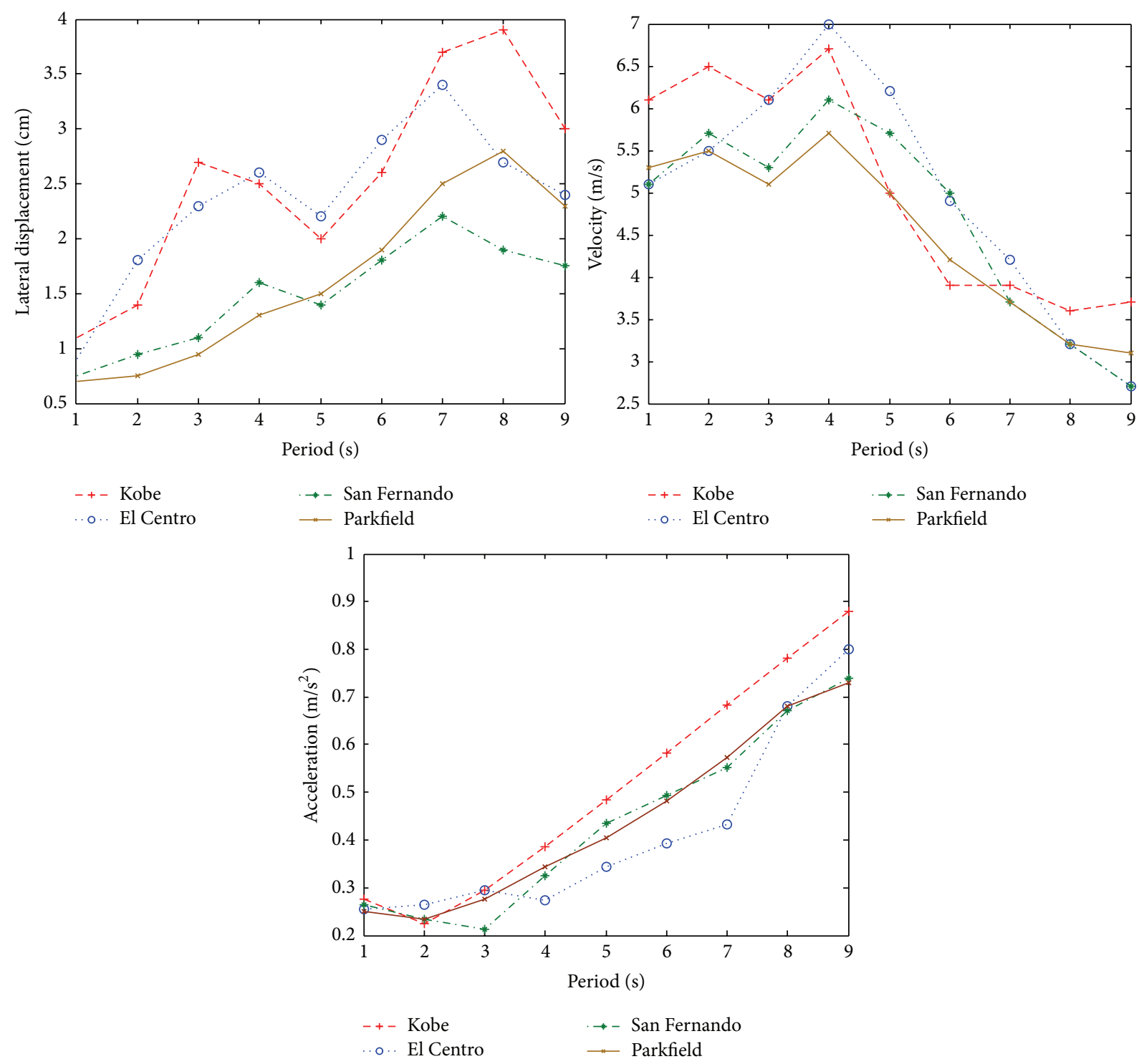

FIGURE 8: Peak lateral displacement, velocity, and acceleration with respect to structural period under different earthquakes.

$3342 \mathrm{kN}$ for the Parkfield, San Fernando, Kobe, and El Centro earthquake, respectively.

\section{Conclusions}

In this paper, earthquake-induced pounding between two adjacent buildings has been studied by the application of single degree-of-freedom structural models. Impact has been numerically simulated with the use of a nonlinear viscoelastic model. Special attention has been focused on calculating values of impact forces during collisions which have significant influence of pounding-involved response under ground motions.

The results of the study indicate that the impact force time history depends substantially on the earthquake excitation analyzed. Moreover, the peak impact force during collision is much dependent on such parameters as gap size, coefficient of restitution, impact velocity, and stiffness of impact spring element. The nonlinear viscoelastic model of impact force with the considered relation between the damping coefficient and the coefficient of restitution has also been found to be effective in simulating pounding between structures during seismic excitations.

The conclusions of the study can be very valuable for the purposes of accurate modelling the phenomenon of earthquake-induced structural pounding. This concerns especially the issue of determination of the precise values of impact forces during collisions which are often not studied in the analyses (or the analyses are simplified) since the investigations are rather focused on pounding-involved response 


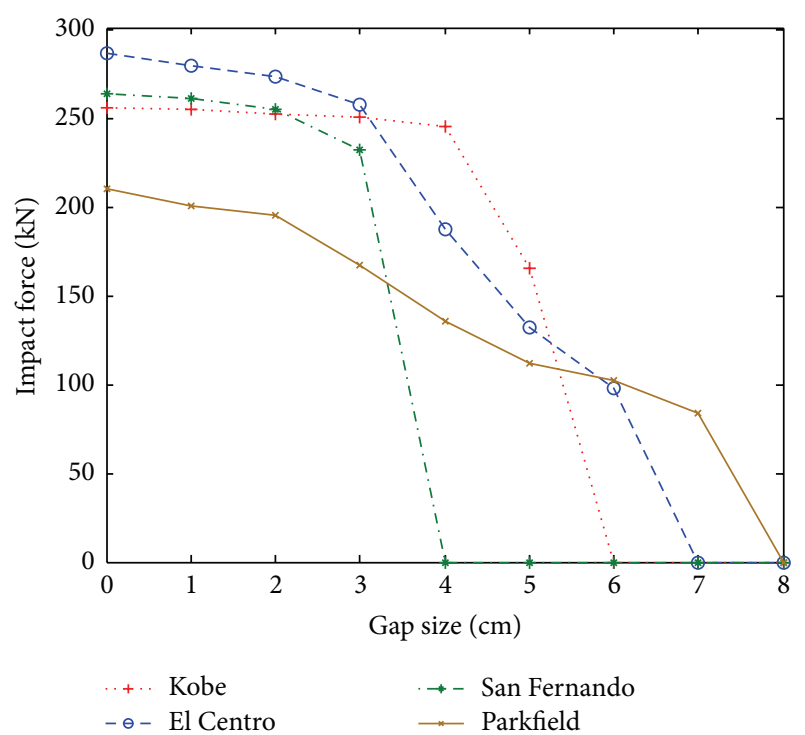

FIGURE 9: Peak impact force with respect to gap size under different earthquakes.

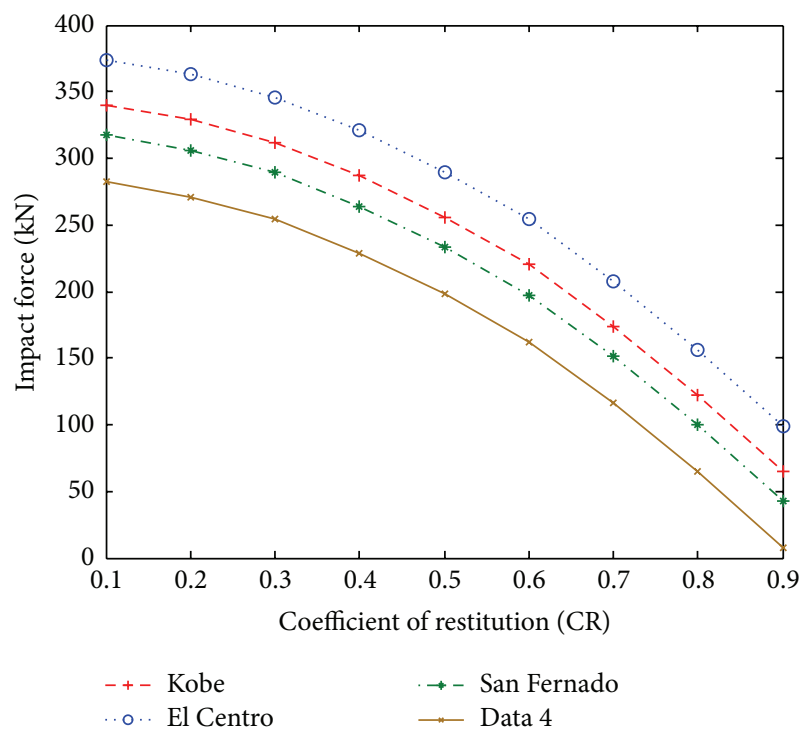

FIGURE 10: Peak impact force with respect to coefficient of restitution under different earthquakes.

under ground motions. It can be considered as the most significant element of the analysis described in this paper, as compared to other relevant research studies.

\section{Conflict of Interests}

The authors declare that there is no conflict of interests regarding the publication of this paper.

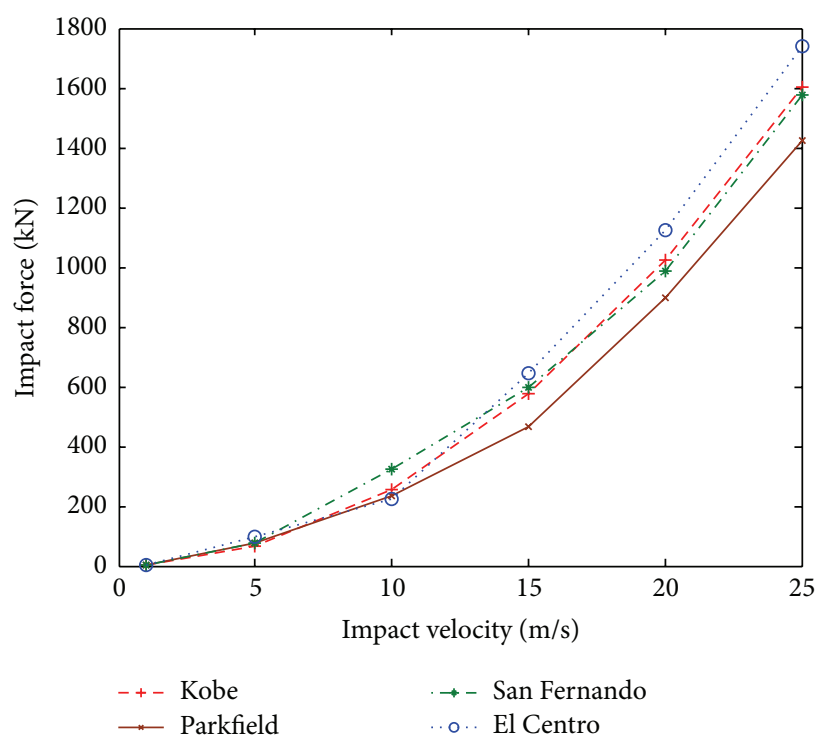

FIGURE 11: Peak impact force with respect to impact velocity under different earthquakes.

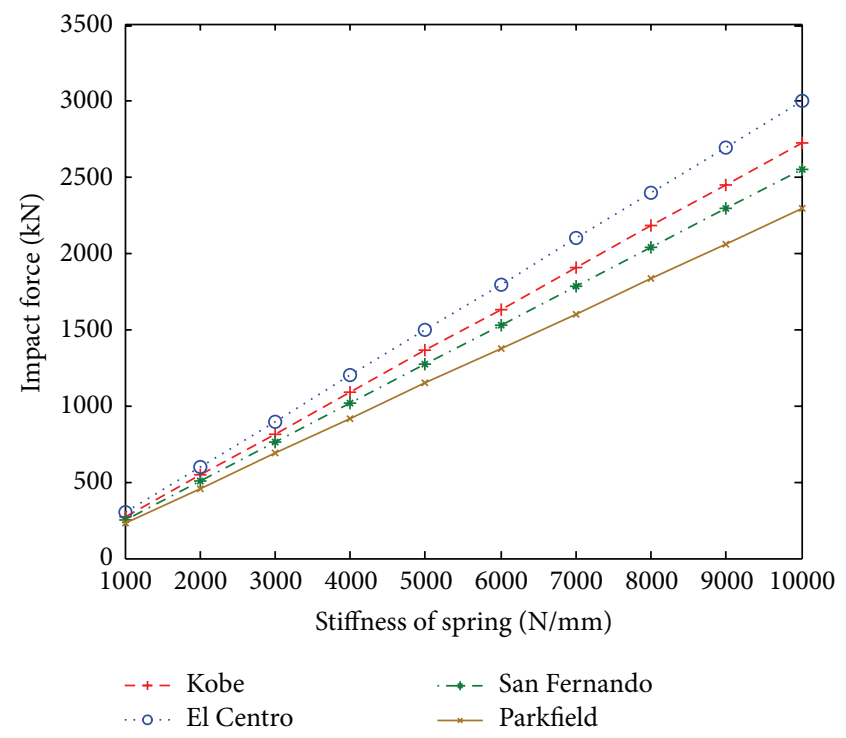

FIGURE 12: Peak impact force with respect to impact spring stiffness under different earthquakes.

\section{References}

[1] K. Kasai and B. F. Maison, "Building pounding damage during the 1989 Loma Prieta earthquake," Engineering Structures, vol. 19, no. 3, pp. 195-207, 1997.

[2] R. Jankowski, "Assessment of damage due to earthquakeinduced pounding between the main building and the stairway tower," Key Engineering Materials, vol. 347, pp. 339-344, 2007.

[3] S. A. Anagnostopoulos, "Pounding of buildings in series during earthquakes," Earthquake Engineering \& Structural Dynamics, vol. 16, no. 3, pp. 443-456, 1988.

[4] S. A. Anagnostopoulos, "Building pounding re-examined: how serious a problem is it?" in Eleventh World Conference on 
Earthquake Engineering, Pergamon, Elsevier Science, Oxford, UK, 1996.

[5] B. F. Maison and K. Kasai, "Dynamics of pounding when two buildings collide," Earthquake Engineering \& Structural Dynamics, vol. 21, no. 9, pp. 771-786, 1992.

[6] R. Jankowski, "Non-linear viscoelastic modelling of earthquake-induced structural pounding," Earthquake Engineering \& Structural Dynamics, vol. 34, no. 6, pp. 595-611, 2005.

[7] R. Jankowski, "Theoretical and experimental assessment of parameters for the non-linear viscoelastic model of structural pounding," Journal of Theoretical and Applied Mechanics, vol. 45, no. 4, pp. 931-942, 2007.

[8] S. Mahmoud and R. Jankowski, "Modified linear viscoelastic model of earthquake-induced structural pounding," Iranian Journal of Science and Technology, vol. 35, no. C1, pp. 51-62, 2011.

[9] S. Mahmoud, A. Abd-Elhamed, and R. Jankowski, "Earthquake-induced pounding between equal height multi-storey buildings considering soil-structure interaction," Bulletin of Earthquake Engineering, vol. 11, no. 4, pp. 1021-1048, 2013.

[10] P. Komodromos, P. C. Polycarpou, L. Papaloizou, and M. C. Phocas, "Response of seismically isolated buildings considering poundings," Earthquake Engineering \& Structural Dynamics, vol. 36, no. 12, pp. 1605-1622, 2007.

[11] P. C. Polycarpou and P. Komodromos, "Numerical investigation of potential mitigation measures for poundings of seismically isolated buildings," Earthquakes and Structures, vol. 2, no. 1, pp. 1-24, 2011.

[12] P. Komodromos and P. Polycarpou, "A nonlinear impact model for simulating the use of rubber shock absorbers for mitigating the effect of structural pounding during earthquake," Earthquake Engineering \& Structural Dynamics, vol. 42, pp. 81-100, 2012.

[13] R. C. Barros and S. M. Khatami, "Damping ratios for pounding of adjacent building and their consequence on the evaluation of impact forces by numerical and experimental models," Mecânica Experimental, vol. 22, pp. 119-131, 2013.

[14] R. C. Barros, H. Naderpour, S. M. Khatami, and A. R. Mortezaei, "Influence of seismic pounding on RC buildings with and without base isolation system subject to near-fault ground motions," Journal of Rehabilitation in Civil Engineering, vol. 1, no. 1, pp. 39-52, 2013.

[15] H. Naderpour, R. C. Barros, and S. M. Khatami, "A new model for calculating the impact force and the energy dissipation based on CR-factor and impact velocity," Scientia Iranica, vol. 22, no. 1, pp. 48-63, 2014.

[16] G. Cole, R. Dhakal, A. Carr, and D. Bull, "An investigation of the effects of mass distribution on pounding structures," Earthquake Engineering \& Structural Dynamics, vol. 40, no. 6, pp. 641-659, 2011.

[17] S. Yaghmaei-Sabegh and N. Jalali-Milani, "Pounding force response spectrum for near-field and far-field earthquakes," Scientia Iranica, vol. 19, no. 5, pp. 1236-1250, 2012.

[18] E. Tubaldi, M. Barbato, and S. Ghazizadeh, "A probabilistic performance-based risk assessment approach for seismic pounding with efficient application to linear systems," Structural Safety, vol. 36-37, pp. 14-22, 2012.

[19] C. Zhai, S. Jiang, S. Li, and L. Xie, "Dimensional analysis of earthquake-induced pounding between adjacent inelastic MDOF buildings," Earthquake Engineering \& Engineering Vibration, vol. 14, no. 2, pp. 295-313, 2015.
[20] B. Madani, F. Behnamfar, and H. Tajmir Riahi, "Dynamic response of structures subjected to pounding and structuresoil-structure interaction," Soil Dynamics and Earthquake Engineering, vol. 78, pp. 46-60, 2015.

[21] W. Goldsmith, Impact: The Theory and Physical Behavior of Colliding Solids, Edward Arnold, London, UK, 1st edition, 1960.

[22] S. A. Anagnostopoulos, "Equivalent viscous damping for modeling inelastic impacts in earthquake pounding problems," Earthquake Engineering \& Structural Dynamics, vol. 33, no. 8, pp. 897-902, 2004.

[23] S. Muthukumar and R. DesRoches, "A Hertz contact model with non-linear damping for pounding simulation," Earthquake Engineering \& Structural Dynamics, vol. 35, no. 7, pp. 811-828, 2006.

[24] K. Ye, L. Li, and H. Zhu, "A note on the Hertz contact model with nonlinear damping for pounding simulation," Earthquake Engineering \& Structural Dynamics, vol. 38, no. 9, pp. 1135-1142, 2009.

[25] R. Jankowski, "Impact force spectrum for damage assessment of earthquake-induced structural pounding," Key Engineering Materials, vol. 293-294, pp. 711-718, 2005. 


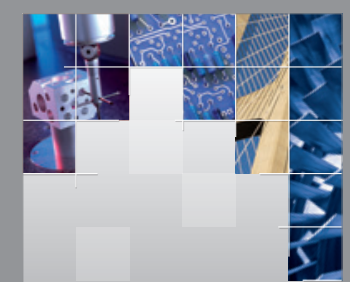

\section{Enfincering}
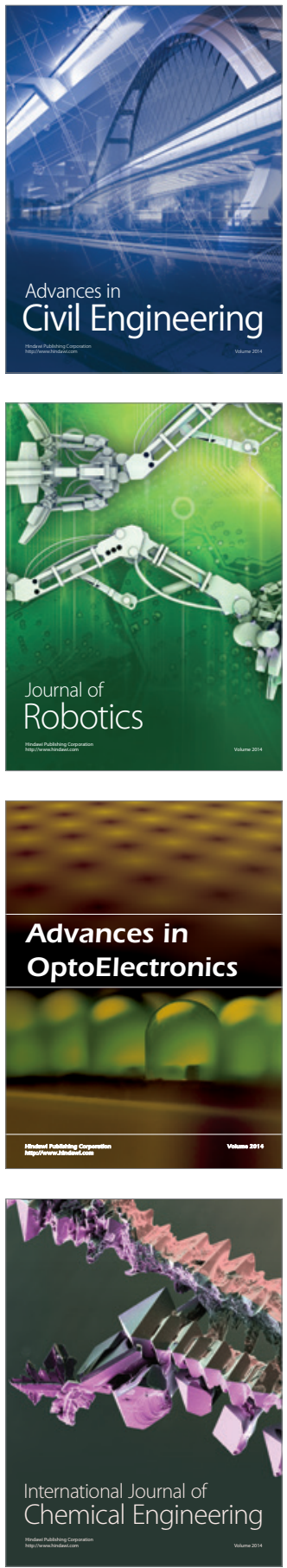

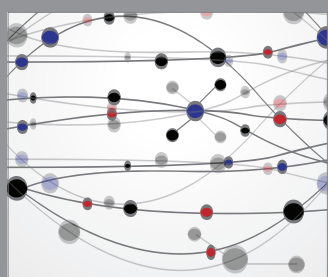

The Scientific World Journal

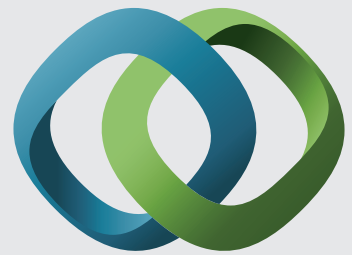

\section{Hindawi}

Submit your manuscripts at

http://www.hindawi.com
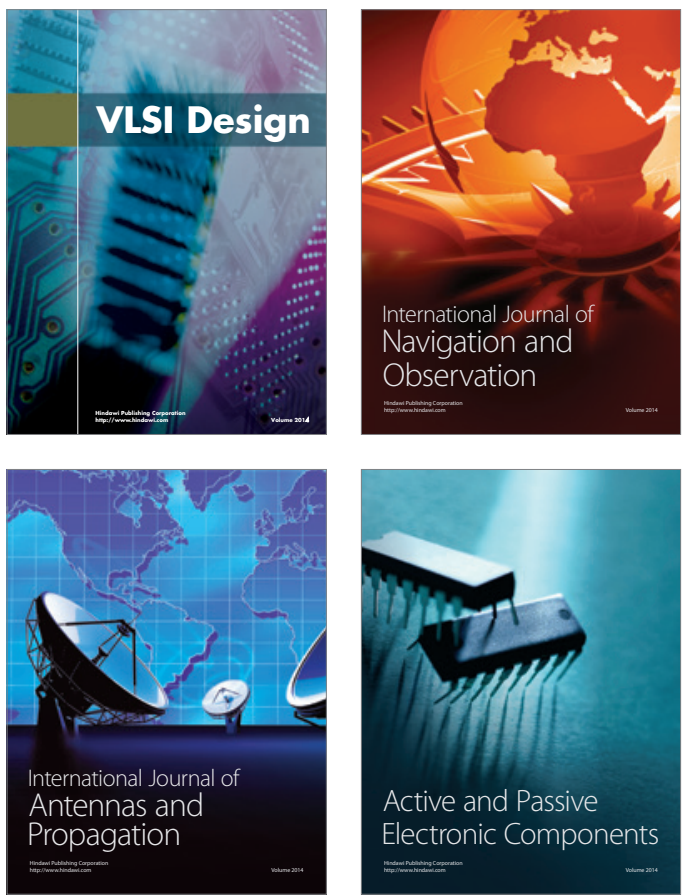
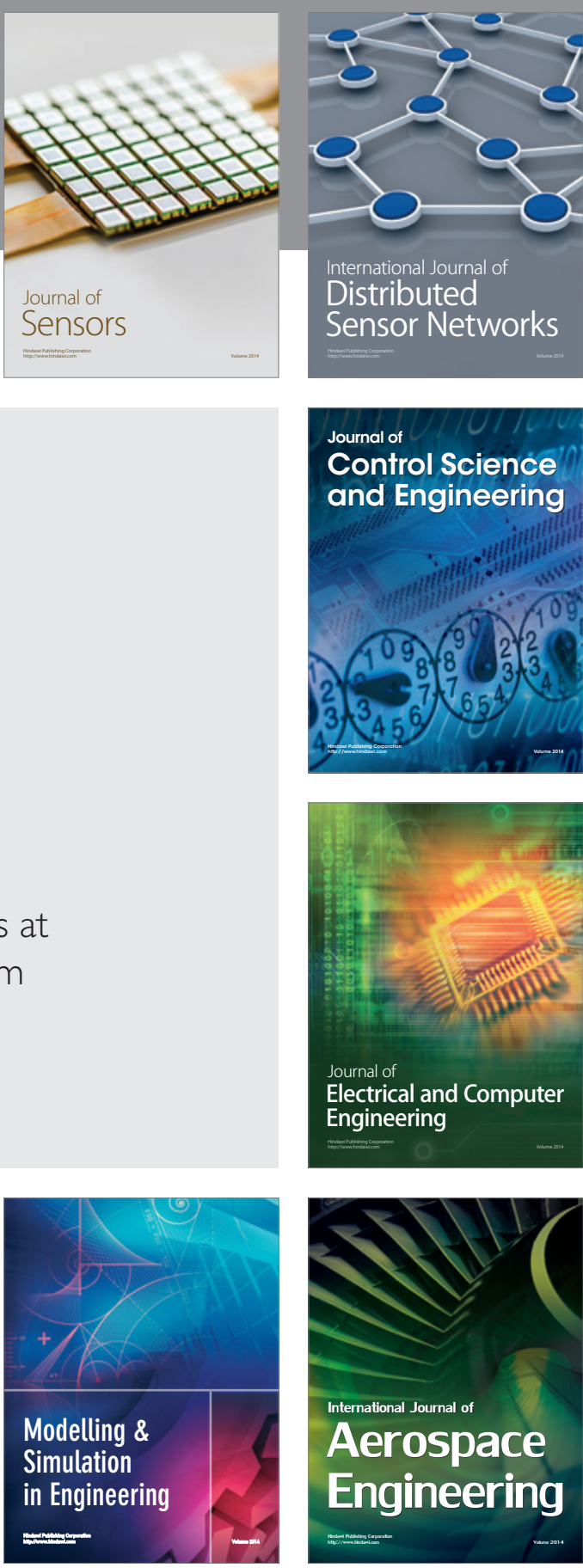

International Journal of

Distributed

Sensor Networks

Journal of

Control Science

and Engineering
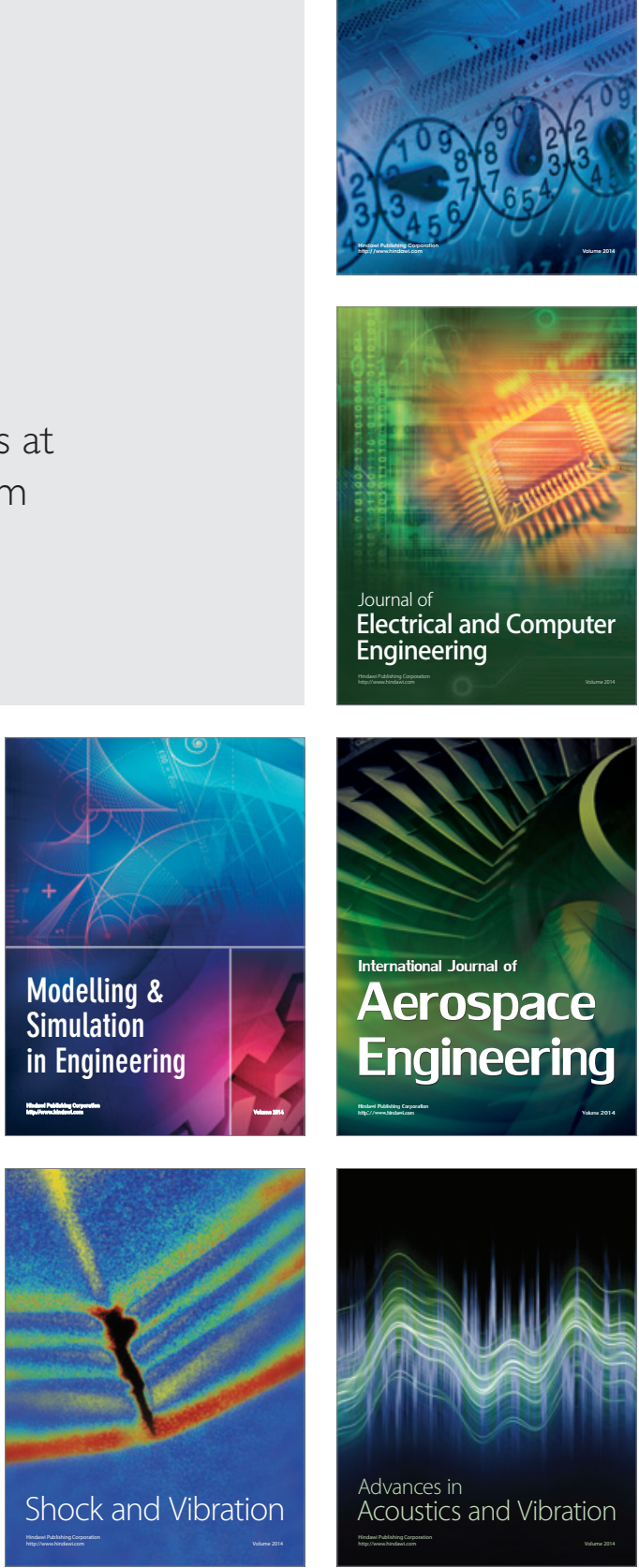